\title{
The peroxisome proliferators-ativated receptor gamma (PPARG) gene polymorphisms and associations with body measurements of cattle
}

\author{
Liushuai Hua, Jing Wang, Fuying Chen, Shenrong Hu, Hong Chen* \\ College of Animal Science and Technology, Northwest A \& F University, Shaanxi Key Laboratory of Molecular Biology \\ for Agriculture, Yangling, Shaanxi 712100, China.
}

Accepted 15 March, 2011

\begin{abstract}
Peroxisome proliferators-activated receptor gamma (PPARG) is an important regulator in the regulation of adipose differentiation and development. The mutations of the PPARG in human had been shown to be associated with type II diabetes, fat distribution and body weight. The functional importance of the PPARG makes it a good candidate to search molecular markers in marker assistant selection in cattle breeding. All the mRNA region of the PPARG gene within 760 individuals of four Chinese cattle breeds was scanned and four single nucleotide polymorphisms (SNPs) $(-110 G>C,-27 C>T,+20 A>G,+1344 G>T)$ of the PPARG were detected in three Chinese indigenous cattle breeds (Qinchuan, Nangyang and Jiaxian cattle), rather than Chinese Holstein cattle. The mutations $-110 G>C,-27 C>T$ and $+20 A>G$ located in the Exon1 of the PPARG and were under linkage disequilibrium. The individuals with these three mutations had smaller body measurements. This information could help animal scientists to develop genetic markers or biomarkers to assist with beef production.
\end{abstract}

Key words: Peroxisome proliferators-activated receptor gamma (PPARG) gene, polymorphisms, cattle, association analysis.

\section{INTRODUCTION}

Adipose tissue is a cell mass contributing not only to the storage of fat, but a sophisticated ensemble of cellular components with highly specialized and complex functions. In addition to managing the most important energy reserve of the body, it secretes a multitude of soluble proteins called adipokines, which have different effects on the homeostasis of the whole body. The expression of these adipokines is an integrated response to various

*Corresponding author. E-mail: chenhong1212@263.net. Tel: +86-029-87092004. Fax: +86-029-87092164

Abbreviations: PPARG, Peroxisome proliferators-activated receptor gamma; MAS, Marker assistant selection; NY, Nanyang; QC, Qinchuan; JX, Jiaxian; CH, Chinese Holstein; PCR-SSCP, polymerase chain reaction single-strand conformation polymorphism; SNPs, single nucleotide polymorphisms; RFLP, restriction fragment length polymorphism; LD, Linkage disequilibrium; BMI, body mass index. signals received from many organs, which depends heavily on the integrity and physiological status of the adipose tissue. One of the main regulators of gene expression in fat is the transcription factor peroxisome proliferators-activated receptor gamma (PPARG), which is a fatty acid- and eicosanoid-dependent nuclear recaptor that plays key roles in the development and maintenance of the adipose tissue (Anghel and Wahli, 2007). Furthermore, synthetic PPARG agonists are therapeutic agents used in the treatment of type II diabetes (Moller, 2001). Evidence from studies of humans and mice has indicated PPARG to be not only a key factor for adipogenesis but also a critical determinant of body fat distribution (Tsai and Maeda, 2005). Association analysis of the PPARG Pro12Ala variants reveals opposing associations with body weight (Deeb et al., 1998; Ek et al., 1999; Doney et al., 2002). The functional importance of PPARG makes it a good candidate to search molecular markers in Marker Assistant Selection (MAS) in cattle breeding. The study would search the mutations of PPARG in several Chinese indigenous cattle breeds, and analyse the associations between the mutations 
Table 1. Primers for Exon1 to Exon7 of PPARG gene in cattle.

\begin{tabular}{|c|c|c|c|}
\hline Loci & Sequence & $\operatorname{Tm}\left({ }^{\circ} \mathrm{C}\right)$ & Length (bp) \\
\hline \multirow[t]{2}{*}{ Exon1 } & 5' CAGCCCAATCTGGAGGTGAC 3' & 64 & 362 \\
\hline & 5' CAGTGAACAGCCTTATGACGC 3' & & \\
\hline \multirow[t]{2}{*}{ Exon2 } & 5' CTGGGAGCATTTACCCTACT 3' & 62 & 350 \\
\hline & 5' CTCAGGGCTAACGTCACAG 3' & & \\
\hline \multirow[t]{2}{*}{ Exon3 } & 5' TTTTCCTGTGATGATTGTCTG 3' & 63 & 281 \\
\hline & 5' CAACACGAAATGAAAACCTA 3' & & \\
\hline \multirow[t]{2}{*}{ Exon4 } & 5' TCCCTCGCCCATATTCCT 3' & 56 & 213 \\
\hline & 5' TAGCAGCCGTGATGAGAAG 3' & & \\
\hline \multirow[t]{2}{*}{ Exon5 } & 5' CTCATTCATCCTGCССТTTC 3' & 56 & 261 \\
\hline & 5' CCCCAAATGAAGACAGTAGAAG $3^{\prime}$ & & \\
\hline \multirow[t]{2}{*}{ Exon6 } & 5' TTCCAACTCAGCCACTTTC $3^{\prime}$ & 56 & 503 \\
\hline & 5' CCAGCAGCAGCTTACCTC 3' & & \\
\hline \multirow[t]{2}{*}{ Exon7 } & 5' TATGCCTCAGATGTGGGAC $3^{\prime}$ & 57 & 579 \\
\hline & 5' GAGAATGGGGTGGGGAAC 3' & & \\
\hline
\end{tabular}

and the body measurements of cattle.

\section{MATERIALS AND METHODS}

\section{Animals and management}

Blood samples were obtained from 760 individuals of four Chinese cattle breeds: Nanyang (NY, $n=287$ ), Qinchuan (QC, $n=272$ ), Jiaxian (JX, $n=141)$, Chinese Holstein $(C H, n=60)$. The test population of NY and QC cattle were reared in the Henan Nanyang Cattle Conservation Farm and Shaanxi Qinchuan Cattle Conservation Farm of China, respectively. The cattle in the conservation farm were under the same nutrition conditions. The test population of JX cattle were dispersed in the village in Henan province of China. The body measurements (including body height, body length and heart girth) of $95 \mathrm{NY}$ cattle were collected at $6,12,18$ and 24 months, respectively. These body measurements of $112 \mathrm{JX}$ cattle and 84 QC cattle were collected too, which were all more than two years old. Several milk traits (milk fat rate, milk protein rate and 305 ds milk yield) of the $60 \mathrm{CH}$ cattle were collected in the diary cattle farm.

\section{Single nucleotide polymorphisms (SNPs) identification and} genotyping

DNA samples were extracted from blood samples firstly and then polymerase chain reaction single-strand conformation polymorphism (PCR-SSCP) (Zhang et al., 2007) was used to scan the mutant of the PPARG. The primers for the seven Exons of PPARG were designed individually (Table 1).

The PCR products with different PCR-SSCP patterns were sequenced to find the mutations within the PPARG and then, PCRrestriction fragment length polymorphism (RFLP) (Michael et al., 1998) was used to investigate the genotypes of the four SNPs ($110 \mathrm{G}>\mathrm{C}, \quad-27 \mathrm{C}>\mathrm{T},+20 \mathrm{~A}>\mathrm{G},+1344 \mathrm{G}>\mathrm{T}$ ) individually. Mutation $110 \mathrm{G}>\mathrm{C},-27 \mathrm{C}>\mathrm{T}$ and $+20 \mathrm{~A}>\mathrm{G}$ was located in Exon1. The primers for this region were Forward: 5' AAACGGACGTCTTGGCTCATT 3'; Reverse: 5' CTCTCTGGGTCAATAAGAGGA 3'. Mutations -110G>C and $-27 \mathrm{C}>\mathrm{T}$ can be detected by restriction enzyme Banl and Hinfl, respectively. A mutation was induced to the forward primer to remove a Hinfl restriction enzyme site, which is no polymorphism in the test breeds, for a clear background of the Hinfl electrophoresis pattern. Another mutation was induced to the reversed primer to add a Sau96I restriction enzyme site, so that forced PCR-RFLP can be used to investigate the genotype of mutation $+20 A>G$. Mutation $+1344 \mathrm{G}>\mathrm{T}$ located in the Exon7 of PPARG, could be detected by restriction enzyme $P$ stl naturally. The allele assigned of the four mutations is presented in Table 2.

\section{Statistical analysis}

Linkage disequilibrium of the SNPs and haplotype frequencies were estimated through PowerMarker (Liu and Muse, 2005). The general linear model (GLM) in the Statistical Package for Social Sciences (SPSS) (version 13.0) was used to evaluate the association between the genotypes and haplotypes of PPARG and the body measurements of cattle. Independent variables were PPARG genotype (or haplotype), breed, age and sex. The GLM was displayed as followed:

$\mathrm{Y}_{i j k l m}=\mathrm{u}+\mathrm{G}_{i}+\mathrm{B}_{j}+\mathrm{A}_{k}+\mathrm{S}_{l}+\mathrm{e}_{i j k l m}$

Where, $Y_{i j k l m}$, Observed value; $u$, overall mean for each trait; $G_{i}$, fixed effect associated with $i_{\text {th }}$ genotype; $B_{j}$, fixed effect associated with $\mathrm{j}_{\text {th }}$ breed; $A_{k}$, fixed effect associated with $\mathrm{k}_{\text {th }}$ age; $\mathrm{S}_{l}$, fixed effect associated $\mathrm{l}_{\text {th }}$ sex; $\mathrm{e}_{i j k m l}$, random error.

The least-squares means (LSM) of the GLM were used to determine the level of significance in pairwise comparisons between genotypes classes. LSM also known as population marginal means, are the values for class means after adjustment for all covariates in the model (Al-Shali et al., 2004). Pairwise comparisons of LSMs were performed using Fisher's protected least significant difference (LSD) t-test procedure.

\section{RESULTS}

\section{SNPs genotyping}

The results of PCR-SSCP analysis showed that just the Exon 1 and 7 of PPARG displayed different electrophoresis patterns (Figure 1). The PCR products of the individuals 
Table 2. Allele assign of the SNPs of PPARG gene.

\begin{tabular}{clllll}
\hline \multicolumn{1}{c}{ SNPs } & \multicolumn{2}{c}{ Sequence } & Amino acid & \multicolumn{1}{c}{ Enzyme } & Cleavage site \\
\hline$-110 \mathrm{G}>\mathrm{C}$ & Wild & ggtgcg & - & Banl & No \\
& Mutant & ggtgcc & & GGYRCC & Yes \\
$-27 \mathrm{C}>\mathrm{T}$ & Wild & gagtc & - & Hinfl & Yes \\
& Mutant & gagtt & & GANTC & No \\
& Wild & gatg/cc & Asp7Gly & Sau96I & No \\
& Mutant & ggtg/cc & & GGNCC & Yes \\
& Wild & ctgcag & Gln448His & Pstl & Yes \\
& Mutant & ctgcat & & CTGCAG & No \\
\hline
\end{tabular}

The bold letters showed the mutations which remove or add a specific enzyme cleavage site. The letters in the frame showed an artificial mutation was induced into the sequence to form an enzyme cleavage site. For example, $\mathrm{g} / \mathrm{c}$ means that after the "g" was forcibly changed into "c", the mutation +20A $>\mathrm{G}$ could be detected by Sau96l.

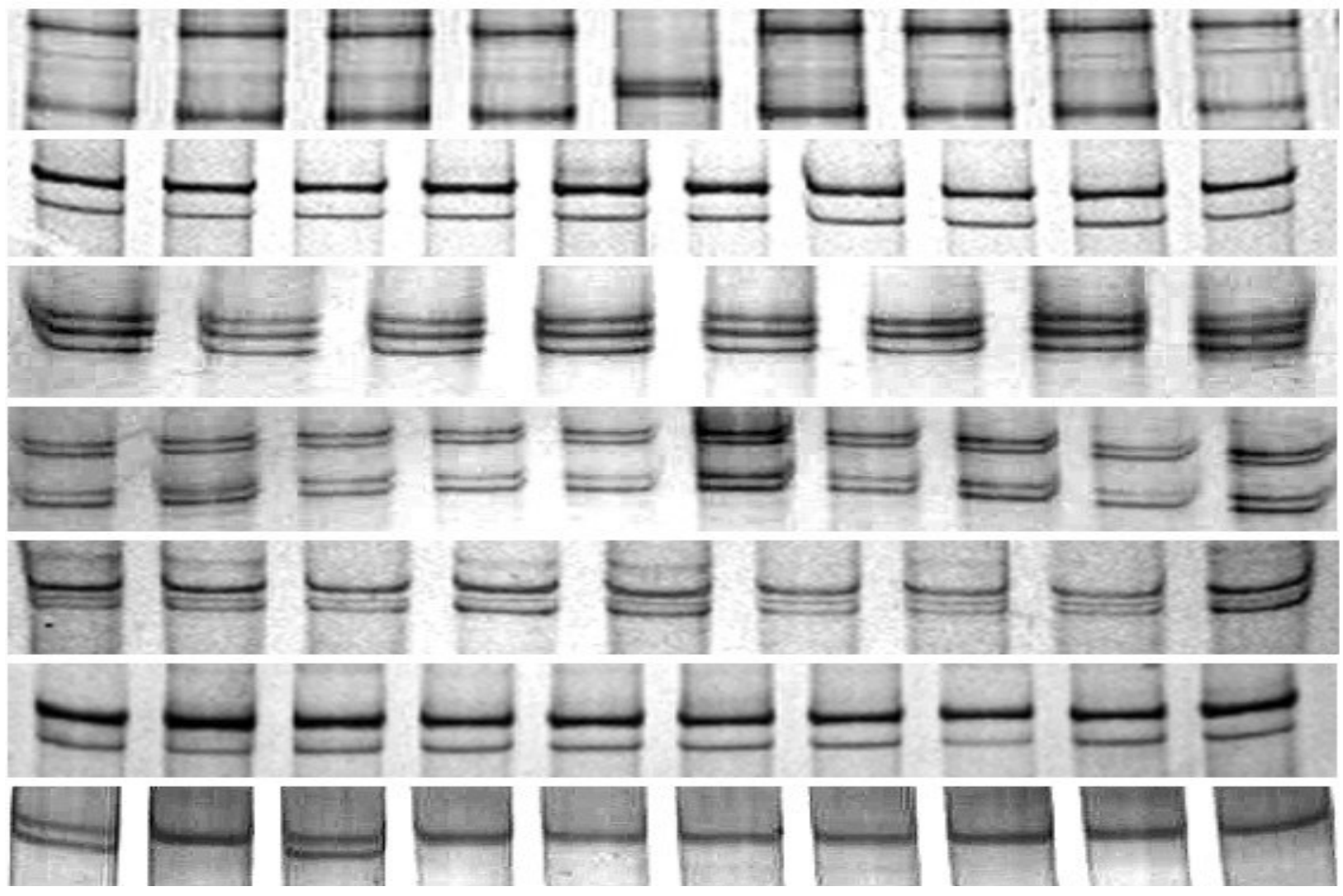

Figure 1. PCR-SSCP patterns of the Exon1 to Exon7 of PPARG gene in cattle. The Exon1 to Exon7 was showed from the top to the bottom. The length of the PCR product from Exon1 to Exon7 was 362, 350, 281, 213, 261,503 and 579 bp, respectively. The electrophoresis voltage was $200 \mathrm{~V}$. The electrophoresis time varied from 2.0 to $3.0 \mathrm{~h}$ depending on the length.

with different electrophoresis pattern were sequenced. Four mutations $(-110 \mathrm{G}>\mathrm{C},-27 \mathrm{C}>\mathrm{T},+20 \mathrm{~A}>\mathrm{G}$ and $+1344 \mathrm{G}>\mathrm{T})$ in the Exonic region of PPARG were detected in the test breeds. Mutations $-110 \mathrm{G}>\mathrm{C}$ and $-27 \mathrm{C}>\mathrm{T}$ located in the 5 ' UTR, add or remove a restriction enzyme site of Banl or Hinfl, respectively. Mutation $+20 A>G$ located in the
Exon1, caused the $7^{\text {th }}$ amino acid changing from Asp to Gly (Asp7Gly). By introducing a mutation to the primer, the mutation Asp7Gly could be genotyped by restriction enzyme Sau96l. Mutation $+1344 G>T$ located in the Exon7 of PPARG, which caused the $448^{\text {th }}$ amino acid changing from Gln to His (Gln448His). The mutation 
Table 3. Genotype and allele frequencies of the SNPs of PPARG gene.

\begin{tabular}{|c|c|c|c|c|c|}
\hline Parameter & Loci & QC & NY & $\mathrm{JX}$ & $\mathrm{CH}$ \\
\hline \multirow{8}{*}{$\begin{array}{l}\text { Genotype } \\
\text { frequency }\end{array}$} & $-110 G>C$ & $266 / 3 / 0 / 269$ & $225 / 27 / 1 / 253$ & $132 / 4 / 0 / 136$ & $55 / 0 / 0 / 55$ \\
\hline & $\begin{array}{l}\left(\mathrm{N}_{\mathrm{GG}} / \mathrm{N}_{\mathrm{GC}} / \mathrm{N}_{\mathrm{CC}} / \mathrm{N}_{\mathrm{T}}\right) \\
\left(\mathrm{P}_{\mathrm{GG}} / \mathrm{P}_{\mathrm{GC}} / \mathrm{P}_{\mathrm{CC}}\right)\end{array}$ & $0.99 / 0.01 / 0$ & $0.89 / 0.10 / 0.01$ & $0.97 / 0.03 / 0$ & $1.00 / 0 / 0$ \\
\hline & $-27 C>T$ & $238 / 31 / 0 / 269$ & $206 / 44 / 3 / 253$ & $109 / 24 / 3 / 136$ & $55 / 0 / 0 / 55$ \\
\hline & $\begin{array}{l}\left(\mathrm{N}_{\mathrm{CC}} / \mathrm{N}_{\mathrm{CT}} / \mathrm{N}_{\mathrm{TT}} / \mathrm{N}_{\mathrm{T}}\right) \\
\left(\mathrm{P}_{\mathrm{CC}} / \mathrm{P}_{\mathrm{CT}} / \mathrm{P}_{\mathrm{TT}}\right)\end{array}$ & $0.88 / 0.12 / 0$ & $0.82 / 0.17 / 0.01$ & $0.80 / 0.18 / 0.02$ & $1.00 / 0 / 0$ \\
\hline & $+20 A>G$ & $251 / 18 / 0 / 269$ & 220/32/1/253 & 123/12/1/136 & $55 / 0 / 0 / 55$ \\
\hline & $\begin{array}{l}\left(\mathrm{N}_{\mathrm{AA}} / \mathrm{N}_{\mathrm{AG}} / \mathrm{N}_{\mathrm{GG}} / \mathrm{N}_{\mathrm{T}}\right) \\
\left(\mathrm{P}_{\mathrm{AA}} / \mathrm{P}_{\mathrm{AG}} / \mathrm{P}_{\mathrm{GG}}\right)\end{array}$ & $0.93 / 0.07 / 0$ & $0.87 / 0.12 / 0.01$ & $0.90 / 0.09 / 0.01$ & $1.00 / 0 / 0$ \\
\hline & $+1344 G>T$ & $184 / 80 / 9 / 273$ & $230 / 35 / 2 / 267$ & $102 / 38 / 0 / 140$ & $50 / 0 / 0 / 50$ \\
\hline & $\begin{array}{l}\left(\mathrm{N}_{\mathrm{GG}} / \mathrm{N}_{\mathrm{GT}} / \mathrm{N}_{\mathrm{TT}} / \mathrm{N}_{\mathrm{T}}\right) \\
\left(\mathrm{P}_{\mathrm{GG}} / \mathrm{P}_{\mathrm{GT}} / \mathrm{P}_{\mathrm{TT}}\right)\end{array}$ & $0.68 / 0.29 / 0.03$ & $0.86 / 0.13 / 0.01$ & $0.73 / 0.27 / 0$ & $1.00 / 0 / 0$ \\
\hline \multirow[t]{4}{*}{$\begin{array}{l}\text { Allele } \\
\text { frequency }\end{array}$} & $\begin{array}{l}-110 G>C \\
\left(P_{G} / P_{C} / H W E \text { test }{ }^{a}\right)\end{array}$ & $0.99 / 0.01 / 1.00$ & $0.94 / 0.06 / 0.56$ & $0.99 / 0.01 / 1.00$ & $1.00 / 0$ \\
\hline & $\begin{array}{l}-27 \mathrm{C}>\mathrm{T} \\
\left(\mathrm{P}_{\mathrm{C}} / \mathrm{P}_{\mathrm{T}} / \mathrm{HWE} \text { test }{ }^{\mathrm{a}}\right)\end{array}$ & $0.94 / 0.06 / 0.58$ & $0.90 / 0.10 / 1.00$ & $0.89 / 0.11 / 0.06$ & $1.00 / 0$ \\
\hline & $\begin{array}{l}+20 A>G \\
\left(P_{A} / P_{G} / H W E \text { test }{ }^{a}\right)\end{array}$ & $0.97 / 0.03 / 0.27$ & $0.93 / 0.07 / 0.61$ & $0.95 / 0.05 / 0.04$ & $1.00 / 0$ \\
\hline & $\begin{array}{l}+1344 G>T \\
\left(P_{G} / P_{T} / H W E \text { test }^{a}\right)\end{array}$ & $0.82 / 0.18 / 0.68$ & $0.93 / 0.07 / 0.64$ & $0.86 / 0.14 / 0.13$ & $1.00 / 0$ \\
\hline
\end{tabular}

${ }^{a}$ The $p$-value greater than 0.05 means the locus was under Hardy-Weinberg equilibrium in the test population.

Table 4. Multi-locus linkage disequilibrium analyses of the SNPs of PPARG gene.

\begin{tabular}{cccc}
\hline Loci & QC $^{\text {a }}$ & NY & JX \\
\hline$-110 G>C--27 C>T-+20 A>G$ & $<0.01$ & $<0.01$ & $<0.01$ \\
$+20 A>G-+1344 G>T$ & 0.78 & 1.00 & 0.06 \\
\hline
\end{tabular}

${ }^{a}$ The $p$-value smaller than 0.05 means these loci were under linkage disequilibrium.

Gln448His could be genotyped by restriction enzyme Pstl naturally. The genotype and allele frequencies of the four mutations are shown in Table 3. No mutations were detected in the $\mathrm{CH}$ breed, except the mutation $+20 \mathrm{~A}>\mathrm{G}$ in the $\mathrm{JX}$ breed, all mutations in the test breeds were under Hardy Weinberg equilibrium.

\section{Linkage disequilibrium (LD) and haplotype analysis}

Multi-locus linkage disequilibrium test of the four SNPs are shown in Table 4. The mutations $-110 \mathrm{G}>\mathrm{C},-27 \mathrm{C}>\mathrm{T}$ and $+20 A>G$ were under linkage disequilibrium in $Q C$, $N Y$ and $J X$ breeds, but the mutation $+1344 G>T$ was not linked with this haplotype block.

\section{Association analysis}

The associations between the four SNPs and the cattle body measurements were analyzed individually (Table 5). The individuals with the mutation $-110 \mathrm{G}>\mathrm{C}$ had smaller body length and heart girth $(P<0.05)$, whereas with the mutations, $-27 \mathrm{C}>\mathrm{T}$ and $+20 \mathrm{~A}>\mathrm{G}$ had smaller body height $(P<0.05)$. No association was observed between the mutation $+1344 G>T$ and the body measurements of cattle.

The difference between the wild haplotype GG-CC-AA and the mutant haplotype GC-CT-AG is shown in Table 6. The individuals with haplotype GC-CT-AG had smaller body length and heart girth $(P<0.05)$, which also means the mutations $-110 \mathrm{G}>\mathrm{C},-27 \mathrm{C}>\mathrm{T}$ and $+20 \mathrm{~A}>\mathrm{G}$ had a negative effects on the body measurements of cattle.

\section{DISCUSSION}

All three types of peroxisome proliferator-activated receptor (PPARG, PPARA and PPARD) are important 
Table 5. Associations between the four SNPs and the body measurements of cattle.

\begin{tabular}{|c|c|c|c|c|c|c|c|c|c|c|c|c|}
\hline \multirow{2}{*}{$\begin{array}{c}\text { Body } \\
\text { measurement }\end{array}$} & \multicolumn{3}{|c|}{$-110 G>C$} & \multicolumn{3}{|c|}{$-27 C>T$} & \multicolumn{3}{|c|}{$+20 A>G$} & \multicolumn{3}{|c|}{$+1344 G>T$} \\
\hline & GT & LSM & $\mathrm{SE}$ & GT & LSM $^{\text {a }}$ & SE & GT & LSM & $\mathrm{SE}$ & GT & LSM & SE \\
\hline \multirow[t]{3}{*}{ Body height } & $G G$ & 121.74 & 0.24 & CC & $121.80^{\mathrm{a}}$ & 0.25 & $A A$ & $121.76^{\mathrm{a}}$ & 0.25 & $G G$ & 121.64 & 0.28 \\
\hline & GC & 120.09 & 0.88 & CT & $121.93^{\mathrm{a}}$ & 0.67 & $A G$ & $122.00^{\mathrm{a}}$ & 0.71 & GT & 121.95 & 0.53 \\
\hline & $-{ }^{b}$ & & & TT & $116.50^{\mathrm{b}}$ & 2.23 & GG & $112.50^{\mathrm{b}}$ & 3.89 & TT & 122.36 & 1.53 \\
\hline \multirow[t]{3}{*}{ Body length } & GG & $134.42^{a}$ & 0.40 & $\mathrm{CC}$ & 134.7 & 0.41 & $A A$ & 134.48 & 0.41 & GG & 134.37 & 0.45 \\
\hline & GC & $131.24^{b}$ & 1.46 & CT & 132.95 & 1.11 & $A G$ & 133.87 & 1.19 & GT & 134.02 & 0.88 \\
\hline & - & - & - & TT & 139.67 & 3.7 & GG & 139 & 6.5 & TT & 129.94 & 2.52 \\
\hline \multirow[t]{3}{*}{ Heart girth } & GG & $165.04^{\mathrm{a}}$ & 0.45 & CC & 165.12 & 0.47 & AA & 164.99 & 0.47 & GG & 165 & 0.51 \\
\hline & GC & $160.74^{b}$ & 1.66 & CT & 165.24 & 1.27 & $A G$ & 165.56 & 1.35 & GT & 164.79 & 0.98 \\
\hline & - & - & - & TT & 168 & 4.23 & GG & 168 & 7.34 & TT & 162.67 & 2.82 \\
\hline
\end{tabular}

${ }^{a} p$ Values of non-random difference between LSMs in pairwise comparisons were estimated in the general linear models procedure. Within a column, LSMs without a common superscript differ $(p<0.05) ;{ }^{b}$ '-' in the table means the genotype was not detected in the test breed.

Table 6. Associations between the haplotypes of PPARG gene and the body measurements of cattle.

\begin{tabular}{lcccc}
\hline Body measurement & Haplotypes & LSM $^{\text {a }}$ & SE & P-value \\
\hline \multirow{2}{*}{ Body height } & GG-CC-AA & 121.80 & 0.25 & 0.06 \\
& GC-CT-AG & 120.09 & 0.87 & \\
Body length & GG-CC-AA & $134.70^{\mathrm{a}}$ & 0.41 & 0.02 \\
& GC-CT-AG & $131.24^{\mathrm{b}}$ & 1.42 & \\
Heart girth & & & & \multirow{2}{*}{0.01} \\
& GG-CC-AA & $165.12^{\mathrm{a}}$ & 0.47 & \\
\hline
\end{tabular}

${ }^{a} p$ Values of non-random difference between LSMs in pairwise comparisons were estimated in the general linear models procedure. Within a column, LSMs without a common superscript differ $(p<0.05)$.

regulators of lipid metabolism. Although, they share significant structural similarity, the biological effects associated with each PPAR isotype are distinct. For example, PPARA and PPARD regulate fatty acid catabolism, whereas PPARG controls lipid storage and adipogenesis. The different functions of PPARs in vivo can be explained as part by the different $\mathrm{N}$ terminus structure (Hummasti and Tontonoz, 2006). This implies that the mutations located at the 5' of the PPARs potentially had important influence on the phenotype. The validated function of Pro12Ala existing in Exon1 of human PPARG also proved the functional importance of this locus (Deeb et al., 1998; Ek et al., 1999; Doney et al., 2002). The mutations $-110 \mathrm{G}>\mathrm{C},-27 \mathrm{C}>\mathrm{T}$ and $+20 \mathrm{~A}>\mathrm{G}$ existed in the same region of PPARG in cattle, which means that these variations potentially have important regulatory roles in the body development. The negative effects to the body measurements of these mutations were similar with the mutation Pro12Ala in human, which is also associated with lower body weight (Doney et al., 2002). But the mechanism of how these mutations affect the body development is unknown yet. The Mutation $+1344 G>T$ did not show any influence in the body measurements in the test breeds though it caused an amino acid change (Gln448His). Different situation is in human where the mutation $1431 \mathrm{C}>\mathrm{T}$ was consistently associated with higher body mass index (BMI) and also linked with the mutation Pro12Ala (Doney et al., 2002).

Since the PPARG is crucial in adipose differentiation, it is expected that the mutations in the PPARG could affect the milk traits. But four of the mutations were just detected in the three Chinese indigenous breeds (QC, NY, JX), rather than $\mathrm{CH}$. A possible explanation is the negative selection against these mutations. QC, NY and JX are all indigenous Chinese cattle breeds. They were not as highly selected as $\mathrm{CH}$, which was selected just for milk production for a long time. Another explanation is breed difference, for example, we also could not identify the mutation Ala18Val in test Chinese cattle breeds, which was reported in Japanese Black cattle (Katsuhiro et al., 1999).

The increased amount of the molecular markers asso- 
ciated with cattle performance were reported (Ge et al., 2003; Schenkel et al., 2005; Zhang et al., 2008), but before using these mutations in a marker assisted selection program, this association should be validated in the target population. The cattle performances are complicated traits which are regulated by lots of factors, so the associations between the molecular markers and the performance can be different in different populations. Some markers regulate the body development through the linkage with some unknown functional mutations and this association could be lost due to recombination.

Four mutations were identified in the PPARG gene of Chinese cattle. Three of which under linkage equilibrium were associated with lower body measurements. This information could help animal scientists to develop genetic markers or biomarkers in cattle breeding, individuals with these mutations should be eliminated through selection. According to the biological function of the PPARG, it is worthy to investigate the associations between these mutations and the meat quality traits in the next study.

\section{ACKNOWLEDGEMENTS}

This study was supported by the National Natural Science Foundation of China (No. 30972080), National Key Technology R\&D Program (No. 2008ADB2B03-19), Keystone Project of Transfergene in China (No. 2009ZX08009-157B, 2008ZX08007-002 and 2009ZX08007-005B-07), Program of National Beef Cattle Industrial Technology System, Basic and Foreland Technology Study Program of Henan Province (No.072300430160), National "863" Program of China (No. 2008AA101010).

\section{REFERENCES}

Al-Shali KZ, House AA, Hanley AJG, Khan HMR, Harris SB, Zinman B, Mamakeesick M, Fenster A, Spence JD, Hegele RA (2004). Genetic Variation in PPARG Encoding Peroxisome Proliferator-Activated Receptor gamma Associated With Carotid Atherosclerosis. Stroke, 35(9): 2036-2040.

Anghel SI, Wahli W (2007). Fat poetry: a kingdom for PPAR[gamma]. Cell Res. 17(6): 486-511.
Deeb SS, Fajas L, Nemoto M, Pihlajamaki J, Mykkanen L, Kuusisto J, Laakso M, Fujimoto W, Auwerx J (1998). A Pro12Ala substitution in PPAR[gamma]2 associated with decreased receptor activity, lower body mass index and improved insulin sensitivity. Nat. Genet. 20(3): 284-287.

Doney A, Fischer B, Frew D, Cumming A, Flavell D, World M, Montgomery H, Boyle D, Morris A, Palmer C (2002). Haplotype analysis of the PPARgamma Pro12Ala and C1431T variants reveals opposing associations with body weight. BMC Genet. 3(1): p. 21.

Ek J, Urhammer SA, Sorensen TI, Andersen T, Auwerx J, Pedersen O (1999). Homozygosity of the Pro12Ala variant of the peroxisome proliferation-activated receptor-gamma2 (PPAR-gamma2): divergent modulating effects on body mass index in obese and lean Caucasian men. Diabetologia, 42(7): 892-895.

Ge W, Davis ME, Hines HC, Irvin KM, Simmen RCM (2003). Association of single nucleotide polymorphisms in the growth hormone and growth hormone receptor genes with blood serum insulin-like growth factor I concentration and growth traits in Angus cattle. J. Anim. Sci. 81(3): 641-648.

Hummasti S, Tontonoz P (2006). The Peroxisome Proliferator-Activated Receptor N-Terminal Domain Controls Isotype-Selective Gene Expression and Adipogenesis. Mol. Endocrinol. 20(6): 1261-1275.

Katsuhiro A, Naoto N, Takayuki M, Yukinobu S, Tomiharu M (1999). Genetic Variants of the PPAR.GAMMA.2 Specific Region in Japanese Black Cattle. Anim. Sci. J. 70(7): J1-J5.

Liu K, Muse SV (2005). PowerMarker: an integrated analysis environment for genetic marker analysis. Bioinformatics, 21(9): 21282129.

Michael M Neff, Joseph D Neff, Joanne Chory, Alan E Pepper (1998). dCAPS, a simple technique for the genetic analysis of single nucleotide polymorphisms: experimental applications in Arabidopsis thaliana genetics. Plant J. 14(3): 387-392.

Moller DE (2001). New drug targets for type 2 diabetes and the metabolic syndrome. Nature, 414(6865): 821-827.

Schenkel FS, Miller SP, Ye X, Moore SS, Nkrumah JD, Li C, Yu J, Mandell IB, Wilton JW, Williams JL (2005). Association of single nucleotide polymorphisms in the leptin gene with carcass and meat quality traits of beef cattle. J. Anim. Sci. 83(9): 2009-2020.

Tsai YS, Maeda N (2005). PPARgamma: A Critical Determinant of Body Fat Distribution in Humans and Mice. Trends Cardiovasc. Med. 15(3): 81-85.

Zhang B, Chen H, Hua L, Zhang C, Kang X, Wang X, Pan C, Lan X, Lei $C$ (2008). Novel SNPs of the mtDNA ND5 Gene and Their Associations with Several Growth Traits in the Nanyang Cattle Breed. Biochem. Genet. 46(5): 362-368.

Zhang C, Wang Y, Chen H, Lan X, Lei C (2007). Enhance the efficiency of single-strand conformation polymorphism analysis by short polyacrylamide gel and modified silver staining. Anal. Biochem. 365(2): 286-287. 